\title{
STUDIES ON INTERFERENCE AMONG TREES IN A PLANTATION OF ALTINGIA EXCELSA
}

\author{
KAN-ICHISAKAI*, ANDREASRUMBINO** \\ National Institute of Genetics, Mishina, Japan and Cenderawasih University, \\ Manokwari, Irian Jaya, Indonesia respectively \\ SHINYAIYAMA* and LILIAN U. GADRINAB \\ National Institute of Genetics, Mishima, Japan and Tropical Forest Biology \\ Program, BIOTROP, Bogor, Indonesia respectively
}

\begin{abstract}
A study was made with the use of a 50-year old Altingia excelsa Noronha plantation with 260 standing trees for separating components of density and intraspecific competition. A component of density effect causes overall decrease in growth while that of competition results in a contrasting effect in growth between any pair of neighboring trees. To detect this density effect, it is most appropriate to use an area of ca. $100 \mathrm{~m}^{2}$ irrespective of the experimental area, e.g. circular or quadratic. Competition effect cannot be detected when two individuals are apart more than two meters.

An application of the density and competitive ability to tree breeding is briefly mentioned.
\end{abstract}

\section{INTRODUCTION}

Growth of trees standing in a monospecific population is under considerable influences of associate trees growing in the proximity. The first is the general effect of thickly planted trees and the second is the specific effect of competition between a given pair of neighboring trees. In some cases the so-called allelopathic effect goes on with them though in the present species no sign of its occurrence has been noticed. The density response and the inter-tree competition are very ubiquitous and consequently silviculturally very important, although the two have often been treated by plant ecologists and agronomists as phenomena of the same category. The senior writer of the present paper, however, is of the belief that the density effect is biologically different from the inter-tree competition.

Therefore, in the present study, the writers intend to investigate the density response and the intraspecific competition in a plantation planted more than fifty years ago with seedlings of a tropical tree species Altingia excelsa Noronha of the

\footnotetext{
* Temporarily seconded to BIOTROP.

** BIOTROP Ten-month Research Training Scholar on Forest Plant Genetic Resources, 1 September 1980-30 June 1981.
} 
Interference among trees in a plantation of A/tingia excelsa-Sakai et al.

family Hamamelidaceae. The species is locally called Rasamala and is one of the valuable timber species native to Indonesia. It grows in natural stands in Western Java and is also planted for afforestation. Its wood is heavy, hard and fine-grained and the color is red to blackish brown. It produces a yellow scented rasamala resin which is used in perfumery. It grows in an area of elevation of 500 to 1500 meters above sea level. The rasamala plantation is on a slow increase in the mountainous area of Western Java.

\section{MATERIALS AND METHODS}

Materials for the study have been obtained from an afforested plantation of Altingia excelsa located in the mountainous region of Bandung in the western part of Java, Indonesia. According to a brief document of the Regional Forestry Office, saplings were initially planted at a distance of 3 x 1 meters in 1927. The first thinning was applied in 1932 (5 years after planting), while the second thinning in 1938 or 11 years after planting. Detailed record, however, is not available at present. After 1939, the stand has been left without artificial thinning, though some trees died from the attack of insects or mammals such as forest pig, or due to some other reasons.

Data were taken in February 1981 when the number of trees still growing in the 60 x 90 meters rectangular plot was 268. Measurement was taken on tree height, clear bole height and diameter at breast height (DBH) and exact location of trees.

Estimation of the effect of tree density on the growth of trees has been made in two ways: (1) effect of number of trees growing within a given radius on the growth of a tree standing in the center of the circle (circular plot) and (2) effect of number of trees within a quadrat or a circle on their average growth (quadrate plot or circular plot). The estimation is based on the assumption that the effect of density would be general for every tree standing in a neighborhood.

For estimating the effect of tree density by measuring the central tree, various sizes of the circle from a radius of 2.5 to 7.5 meters have been taken, while the effect of tree number on their average growth has been measured in a quadrat of $10 \times 10$ meters or in circle of a radius of 5 to 6 meters.

For an investigation of intraspecific competition, correlation of DBH between two nearest neighboring trees, on the one hand, and difference in $\mathrm{DBH}$ between them, on the other, have been measured for various inter-tree distances. This is on the assumption that the effect of competition on the growth of a pair of adjoining trees would be antagonistic, i.e. favoring one at the expense of another to yield negative correlation or to enlarge the difference between their DBH's. 


\section{RESULTS OF THE STUDY}

\section{Growth of trees}

Trees of Altingia excelsa in the present plantation have grown after 55 years of planting to an average height of 32.6 meters, though some trees exceeded 40 meters. The $\mathrm{DBH}$ has grown to 33.3 centimeters on the average, with the biggest tree with a value of more than 60 centimeters. The variations in the tree height and DBH are presented in Tables 1 and 2, and graphically but with an increased number of class intervals in Figures 1 and 2.

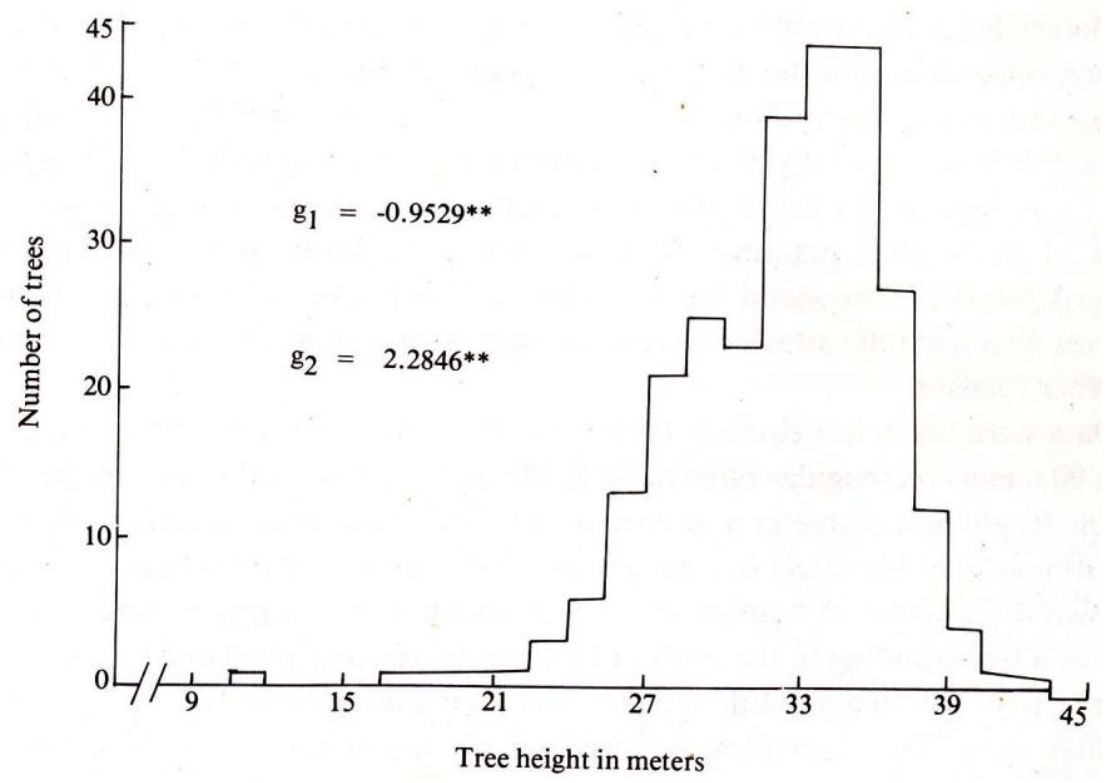

Figure 1. Frequency histogram of tree height of an even-aged stand of Altingia excelsa.

The frequency histogram of the tree height is negatively skewed and leptokurtic (Fig. 1), while that of DBH is positively skewed with an intuitive impression of some multimodality (Fig. 2), though both of the tree height and the DBH were positively correlated with $\mathrm{r}=0.6769^{* *}$ for 266 degrees of freedom. 
Interference among trees in a plantation of Altingia excelsa - Sakai et al.

Table 1. Frequency distribution of height of 268 trees growing in the $60 \times 90 \mathrm{~m}$ rectangle of Altingia excelsa.

\begin{tabular}{ccccccccccc}
\hline \hline $\begin{array}{c}\text { Tree height } \\
(\mathrm{m})\end{array}$ & $\begin{array}{c}12- \\
15\end{array}$ & $\begin{array}{c}16- \\
19\end{array}$ & $\begin{array}{c}20- \\
23\end{array}$ & $\begin{array}{c}24- \\
27\end{array}$ & $\begin{array}{c}28- \\
31\end{array}$ & $\begin{array}{c}32- \\
35\end{array}$ & $\begin{array}{c}36- \\
39\end{array}$ & $\begin{array}{c}40- \\
43\end{array}$ & $\begin{array}{c}\text { Total number } \\
\text { of trees }\end{array}$ & $\begin{array}{c}\text { Mean and } \\
\text { standard } \\
\text { deviation }\end{array}$ \\
\hline $\begin{array}{c}\text { Number of } \\
\text { trees }\end{array}$ & 1 & 2 & 4 & 28 & 65 & 113 & 51 & 4 & 268 & $32.50 \pm 4.23$ \\
\hline
\end{tabular}

Table 2. Frequency distribution of $\mathrm{DBH}$ of 268 trees growing in the $60 \times 90 \mathrm{~m}$ rectangle of Altingia excelsa.

\begin{tabular}{|c|c|c|c|c|c|c|c|c|c|c|c|c|}
\hline $\begin{array}{l}\text { Diameter at } \\
\text { breast height } \\
(\mathrm{cm})\end{array}$ & $\begin{array}{l}15- \\
19\end{array}$ & $\begin{array}{l}20- \\
24\end{array}$ & $\begin{array}{c}25- \\
29\end{array}$ & $\begin{array}{c}30- \\
34\end{array}$ & $\begin{array}{c}35- \\
39\end{array}$ & $\begin{array}{l}40- \\
44\end{array}$ & $\begin{array}{c}45- \\
49\end{array}$ & $\begin{array}{c}50- \\
54\end{array}$ & $\begin{array}{c}55- \\
59\end{array}$ & $\begin{array}{l}60- \\
64\end{array}$ & $\begin{array}{l}\text { Total number } \\
\text { of trees }\end{array}$ & $\begin{array}{l}\text { Mean and } \\
\text { standard } \\
\text { deviation }\end{array}$ \\
\hline $\begin{array}{c}\text { Number of } \\
\text { trees }\end{array}$ & 5 & 46 & 51 & 55 & 54 & 38 & 10 & 6 & 2 & 1 & 268 & $33.30 \pm 8.41$ \\
\hline
\end{tabular}

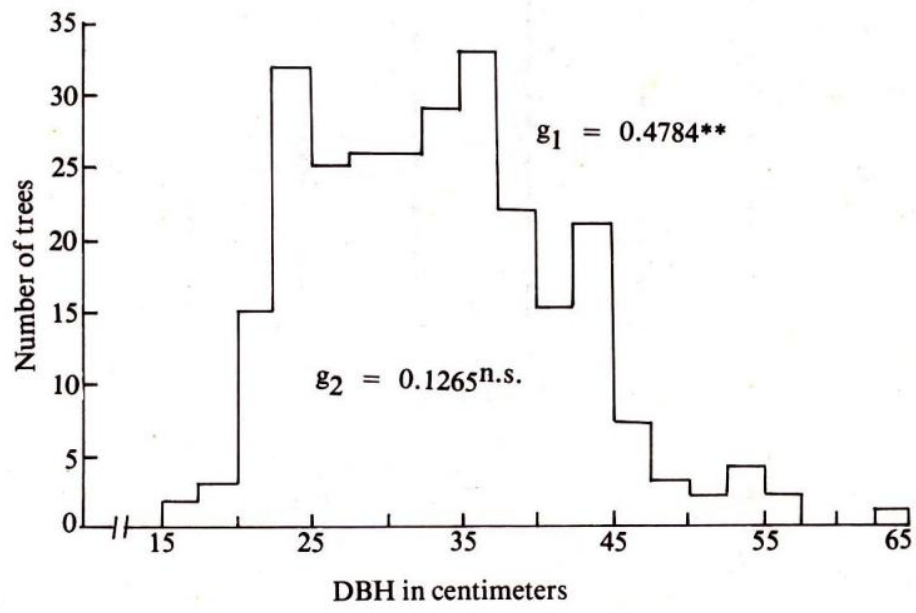

Figure 2. Frequency histogram of diameter at breast height $(\mathrm{DBH})$ of an even-aged stand of Altingia excelsa. 


\section{Density effect}

At first, the density effect was measured by the DBH of a central tree being surrounded by various number of trees growing within a given area of a circular plot. The circular plots were constructed with various radii from 2.5 to 7.5 meters. If the tree density does exert some hindering effect on the growth of trees, the number of trees within a given circle should be negatively correlated with $\mathrm{DBH}$ of the central tree because the higher the density, the poorer is the growth of the central tree would be. The correlation coefficients between them are shown for various sizes of the circle (Table 3).

It is found that a smaller circle with a radius less than 4 meters is too small to include sufficient number of trees to yield apparent density effect. It looks that the most reliable size of the circle for detection of the density effect is a radius of 5 to 6.5 meters with the average of 4.5 to 7 trees growing within the plot. The distribution of DBH of a central tree, averaged for each class, against various number of trees within the radius of 5.5 meters, as an example, is shown in Figure 3.

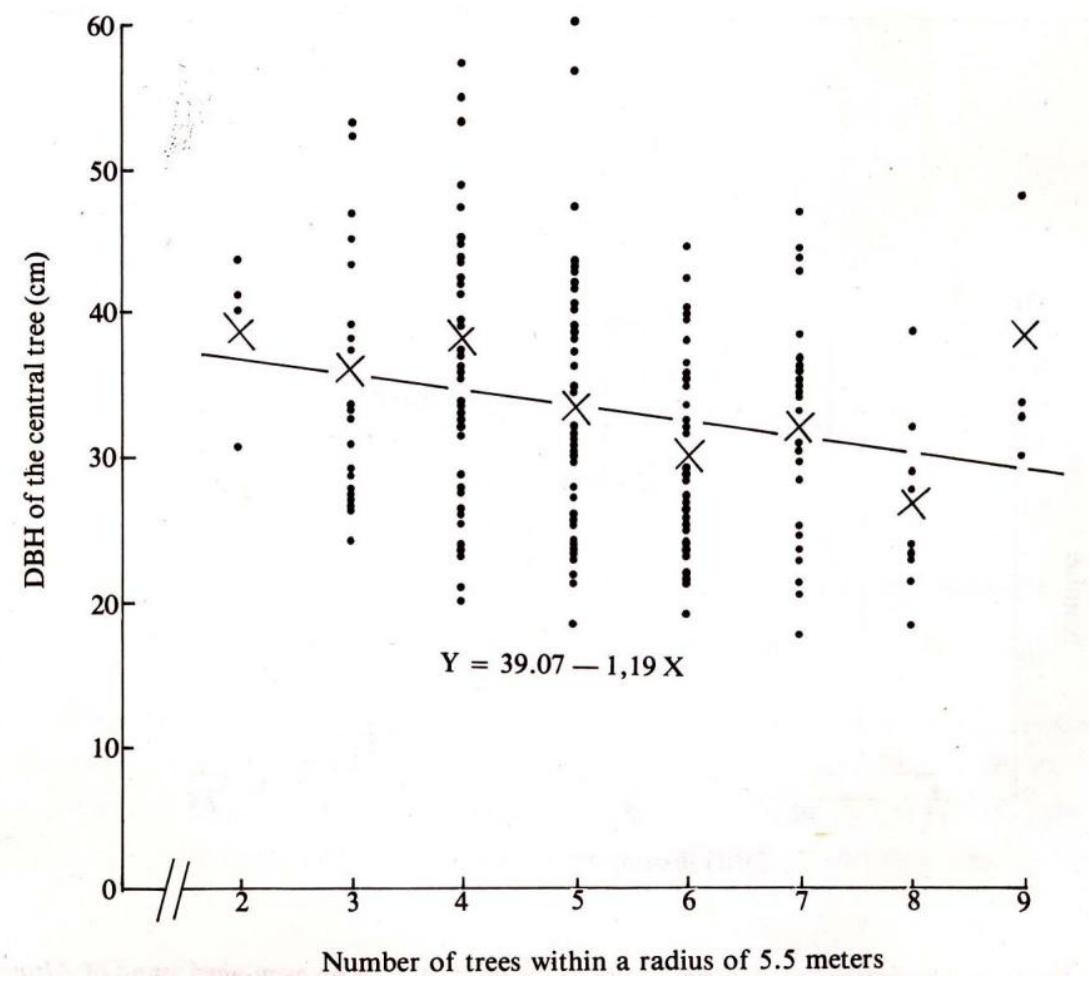

Figure 3. Effect of number of trees coexisting within a radius of 5.5 meters on the DBH growth of a central tree. X: Mean value. 
Interference mong trees in plantation of Altingia excelsa - Sakai et al.

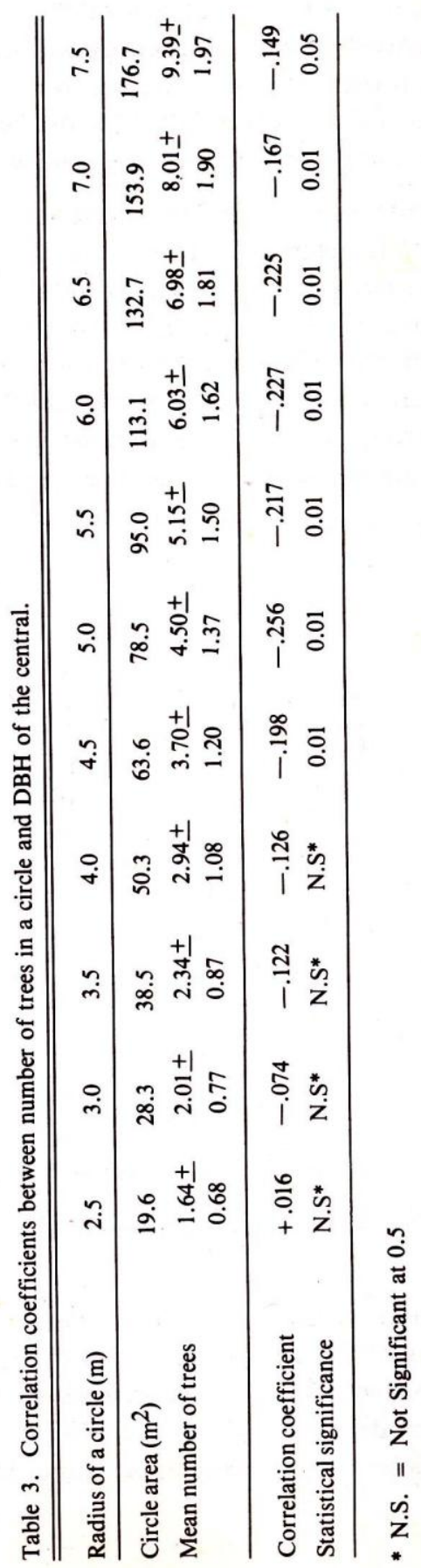


The second approach to the estimation of the density effect was made by measuring the average growth of all trees growing within a given circle. The size of the circular plot was confined to the radii ranging from 5 to 6.5 meters on the basis of the foregoing analysis. The correlation coefficients between the number of trees within a plot of a given radius and their average growth are shown in Table 4.

It shows that the most reliable size of a circle for estimating density response is with a radius of 5.5 to 6.0 meters. The $10 \times 10$ meter quadrat just corresponds to the area of a circle of a radius of 5.64 meters, giving an equivalent correlation of -0.351 . The distribution of $\mathrm{DBH}$ in relation to the number of trees within a limited area with a corresponding regression line is depicted for a circle of 5.5 meter radius in Figure 4 and $10 \times 10$ meter quadrat in Figure 5.

It is concluded from these studies that the response to density in the plantation of Altingia excelsa can be properly detected by measuring mean $\mathrm{DBH}$

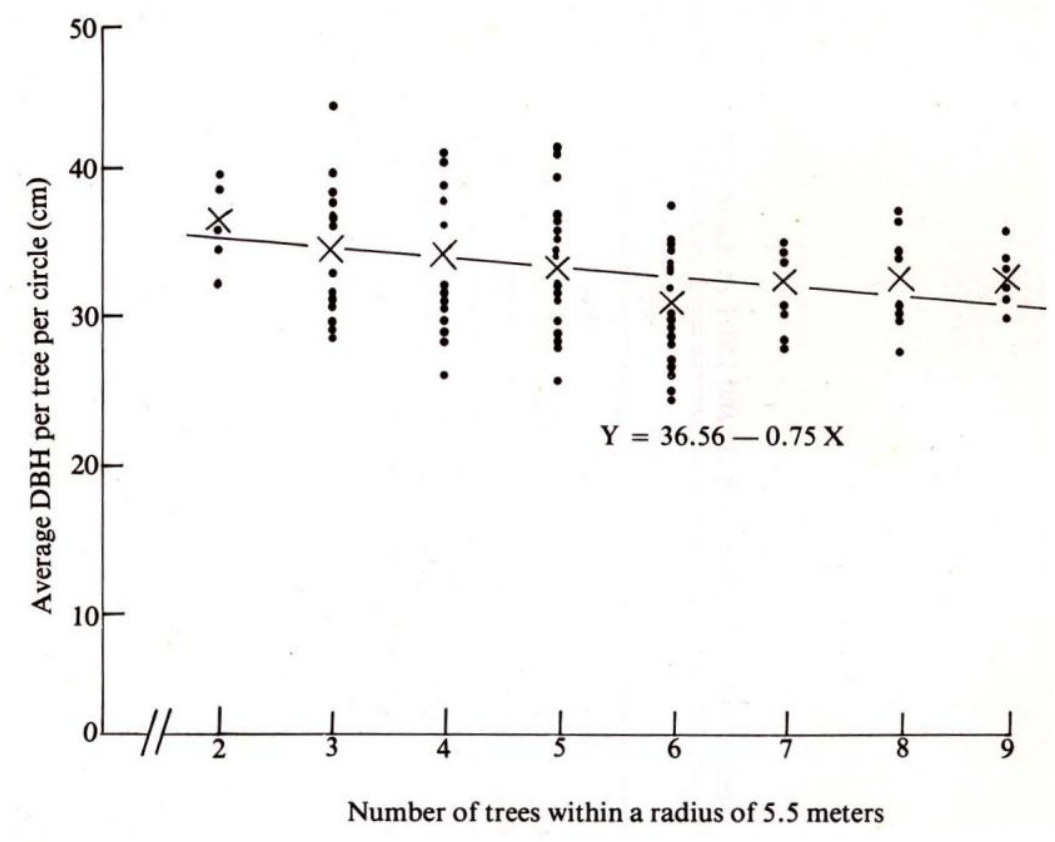

Figure 4. Effect of number of trees coexisting within a radius of 5.5 meters on their DBH growth. X:

Mean value.

growth of trees in relation to their number growing within a radius of 5.5 to 6.0 meters or in quadrats of $10 \times 10$ meters, area of which being approximately between 95 and $110 \mathrm{~m}^{2}$ or just $100 \mathrm{~m}^{2}$ in the case of the quadrat. Measurement of DBH of a single tree for detection of density effect is more or less inaccurate because of high fluctuation in measurements as found in Figure 3 (compare with 
Interference among trees in a plantation of Altingia excelsa - Sakai et al.

Table 4. Correlation coefficients between number of trees and the average growth in DBH of trees growing within the plot for four sizes of the circle and $10 \times 10 \mathrm{~m}^{2}$ quadrat.

\begin{tabular}{|c|c|c|c|c|c|}
\hline Radius in meters & 5.0 & 5.5 & $10 \times 10$ & 6.0 & 6.5 \\
\hline Area $\left(m^{2}\right)$ & 78.5 & 95.0 & 100.0 & 113.1 & 132.7 \\
\hline Number of growing trees & $4.58 \pm 1.35$ & $5.25 \pm 1.58$ & $4.96 \pm 1.60$ & $6.19 \pm 1.63$ & $6.94 \pm 1.80$ \\
\hline $\begin{array}{l}\text { Correlation in circular } \\
\text { plot }\end{array}$ & $-.276^{* *}$ & $-.341^{* *}$ & - & $-.347^{* *}$ & $-.307^{* *}$ \\
\hline Correlation in quadrat & - & - & $-.351^{* *}$ & - & - \\
\hline
\end{tabular}

** Significant at the 0.01 level

Figure 4). Granting that the coefficient of regression described in Figure 4 is correct, we can mention that the response to tree density in Altingia excelsa is -0.75 centimeters in DBH against an increase of one tree in the stand.

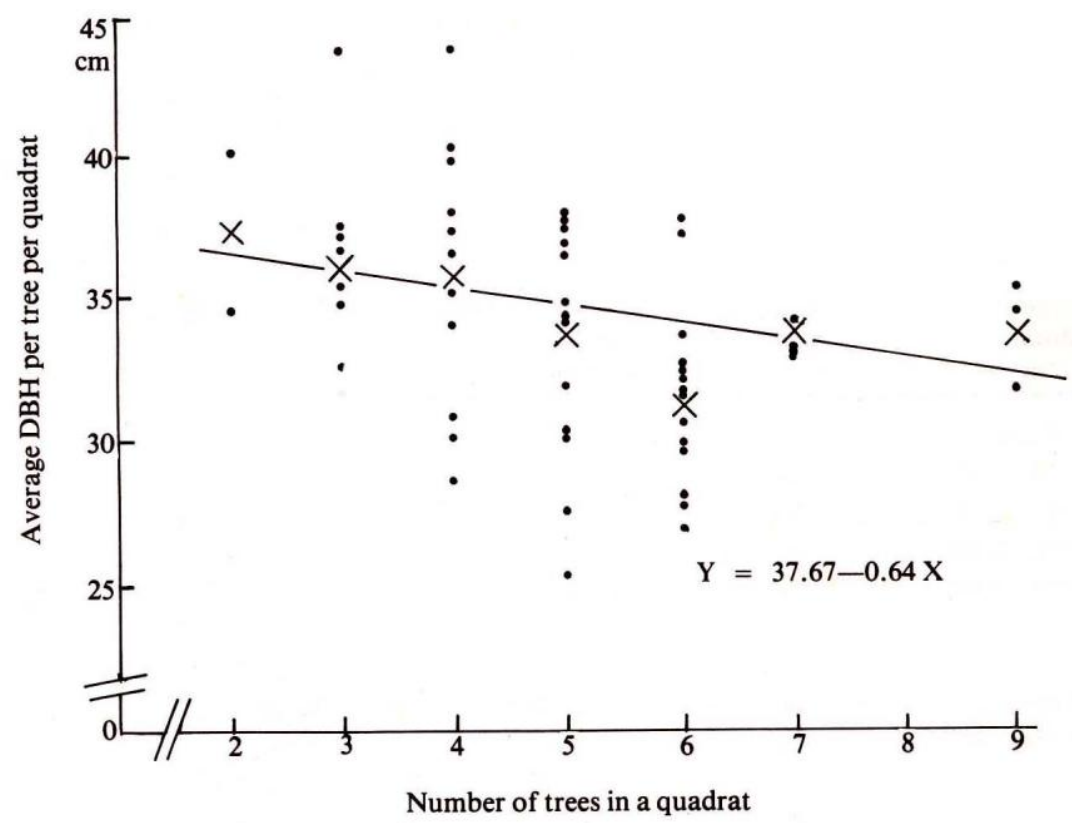

Figure 5. Effect of number of trees coexisting in a 10 x 10 meter quadrat on their DBH growth. X: Mean value. 


\section{Intraspecific competition}

As shown in Figures 3 to 5 , growth of DBH of trees decreases linearly as the number of trees in a limited area increases. Competition between adjoining trees may interrupt the linear decrease in DBH due to the density effect. If competition occurs between two adjoining trees, the growth of the one is favored while that of another is handicapped on the basis of their inherent competitive ability. Thus, a negative correlation results between them. Table 5 shows that the correlation of DBH between two adjoining trees is negative if the inter-tree distance is less than 2 meters. The positive correlation found at the inter-tree distance larger than 2.01 meters indicates that inter-tree competition in Altingia excelsa appears to come into play within a distance of two meters.

In the right column of Table 5 and also in Table 6, the differences in DBH between two adjoining trees in relation to inter-tree distances are described. It is expected naturally that if competition occurs between two adjoining trees, the difference in $\mathrm{DBH}$ between them should be greater by the effect of competition than otherwise. It is found from Table 5 that at a distance less than two meters, the difference in DBH is greater than others; while from Table 6, one notes that at a distance of two meters or less, the distribution of various values of difference in $\mathrm{DBH}$ is not at random, but larger values than 11 are more often observed than theoretically expected.

Table 5. Inter-tree competition in relation to inter-tree distance in Altingia excelsa.

\begin{tabular}{lccc}
\hline $\begin{array}{l}\text { Inter-tree } \\
\text { distance in } \\
\text { meters }\end{array}$ & $\begin{array}{c}\text { Number of } \\
\text { pairs }\end{array}$ & $\begin{array}{c}\text { Correlation of DBH } \\
\text { between two } \\
\text { adjoining trees }\end{array}$ & $\begin{array}{c}\text { Difference in DBH } \\
\text { between two adjoining } \\
\text { trees in centimeters }\end{array}$ \\
\hline$<1.75$ & 11 & $-0.4139 \dagger$ & $14.71 \pm 7.96$ \\
$1.75-2.00$ & 16 & $-0.2276 \mathrm{~J} \dagger$ & $12.63 \pm 7.62$ \\
$2.01-2.25$ & 14 & $+0.6035^{*}$ & $9.65 \pm 7.93$ \\
$2.26-2.50$ & 28 & $+0.1275 \dagger$ & $12.25 \pm 8.08$ \\
$2.51-3.00$ & 30 & $+0.4349^{*}$ & $9.94 \pm 7.65$ \\
$3.01-3.50$ & 27 & $+0.5858^{* *}$ & $7.21 \pm 5.10$ \\
$3.51-4.00$ & 32 & $+0.3703^{*}$ & $8.35 \pm 7.65$ \\
$4.01-4.50$ & 30 & $+0.0259 \dagger$ & $11.12 \pm 7.38$ \\
$4.51-5.00$ & 25 & $+0.6222^{* *}$ & $6.84 \pm 5.27$ \\
$5.01-5.50$ & 15 & $+0.1285^{\dagger}$ & $7.85 \pm 6.92$ \\
$5.51-7.50$ & 21 & $+0.6155^{* *}$ & $7.56 \pm 5.78$ \\
\hline
\end{tabular}

$\dagger$ Falling short of the significance level.

*, ** Significant at the 5 and $1 \%$ levels, respectively. 
Interference among trees in a plantation of Altingia excelsa - Sakai et al.

Table 6. Relation between DBH difference between two adjoining inter-tree distance.

\begin{tabular}{|c|c|c|c|c|c|c|c|}
\hline \multirow{2}{*}{$\begin{array}{l}\text { Inter-tree } \\
\text { distance } \\
\text { (m) }\end{array}$} & \multicolumn{4}{|c|}{ DBH difference between two adjoining trees $(\mathrm{cm})$} & \multirow{2}{*}{ Total } & \multirow{2}{*}{$x^{2}$} & \multirow{2}{*}{$\begin{array}{l}\mathrm{P} \text { for two } \\
\text { degrees of } \\
\text { freedom }\end{array}$} \\
\hline & & $0-10$ & $11-15$ & $>16$ & & & \\
\hline \multirow[t]{2}{*}{$\leqslant$} & Observed & 9 & 10 & 8 & 27 & 13.55 & $<0.01$ \\
\hline & Expected & 17.56 & 4.23 & 5.20 & & & \\
\hline \multirow[t]{2}{*}{$2.01-2.50$} & Observed & 22 & 8 & 12 & 42 & 3.21 & 0.20 \\
\hline & Expected & 27.33 & 6.58 & 8.11 & & & \\
\hline \multirow[t]{2}{*}{$2.51-3.50$} & Observed & 42 & 6 & 9 & 57 & 1.97 & $0.20-0.50$ \\
\hline & Expected & 37.08 & 8.93 & 10.99 & & & \\
\hline \multirow[t]{2}{*}{$3.51-4.50$} & Observed & 42 & 6 & 14 & 62 & 1.84 & $0.20-0.50$ \\
\hline & Expected & 40.34 & 9.71 & 11.95 & & & \\
\hline \multirow[t]{2}{*}{$\geqslant 4.51$} & Observed & 47 & 9 & 5 & 61 & 5.26 & $0.05-0.10$ \\
\hline & Expected & 39.69 & 9.55 & 11.76 & & & \\
\hline
\end{tabular}

Figure 6 shows the distribution of mean differences in $\mathrm{DBH}$ between two adjoining trees at different inter-tree distances from 1.5 to 7.5 meters. The theoretical curve to fit the data can be obtained from the following formula :

$$
\mathrm{Y}=20.574 / \mathrm{X}^{\circ}{ }^{60}
$$

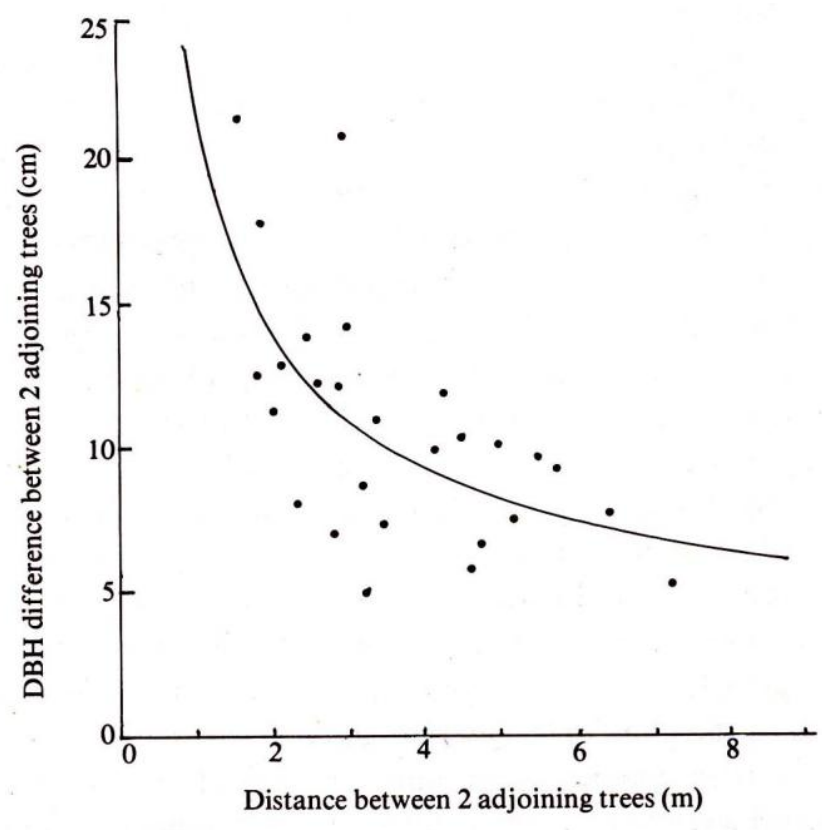

Figure 6. Mean differences in DBH against distances between two adjoining trees. The curve represents theoretical one calculated by $\mathrm{Y}=20.574 / \mathrm{XO}-60$. 
where $\mathrm{Y}$ and $\mathrm{X}$ are DBH difference and inter-tree distance, respectively. The curve suggests that the competitive effect is apparent only when the inter-tree distance is small or less than 2 meters.

\section{DISCUSSION}

As early as some 30 years ago, Koyama and Kira (1956) investigated the frequency distribution of plant weight in experimental populations of several kinds of plants and found that the distribution of girth of trees or weight of annual plants generally showed a positive skewness or the L-shaped distribution though in the initial stage of their growth it took the form of a normal distribution. They concluded from a mathematical study that, assuming normal distribution in the initial plant weight and also in the growth rate, the distribution of plant weight in later stages had to become positively skewed or to show the L-type distribution without additional assumption of interaction among plants. They further found that the frequency distribution of plant height, on the contrary, showed a normal curve or in some cases negative skewness.

Ford (1975) investigated the frequency histograms of girth of trees or weight of annual plants in even-aged plant monocultures and concluded that positive skewness and platykurtosis showing bimodality were characteristic of their distribution. He also observed an even-spatial distribution of large plants in the population. He attributed such an occurrence of positive skewness with bimodality and the even-spatial distribution to the effect of intraspecific competition.

In contrast to these observations, Tanaka (1983) recently published a paper describing an apparently negative, instead of positive, skewness in the distribution histogram of DBH in 42-year-old Cryptomeria japonica plantation.

In Altingia excelsa of the present investigation, the tree height showed highly significant negative skewness together with an apparent peakedness, whereas the DBH showed a significant positive skewness as depicted in Figure 2. In addition, the histogram of DBH seems to be indicative of multimodality rather than bimodality. As described above, Ford is of the opinion that bimodal distribution is an evidence of intraspecific competition, but we hold another view from Ford in that multimodal distribution would be more general than bimodal one under the influence of competition. This is because the competitive ability of a plant is the joint product of environmental or non-heritable effect and the inherent genetic effect of the plant. The environmental effect involves, in addition to those generally regarded factors, such non-heritable effect as an acquired advantage due to earlier germination than others. That competitive ability of a plant is a genetic character and is mostly controlled by the so-called polygenes having so low a heritability as 0.3 or less has been repeatedly demonstrated (Sakai 
1955, Oka 1960, Akihama 1967, 1968). As a matter of fact, it is considered that the competitive ability of plants may involve a complex of capacities concerning exploitation of various kinds of resources with or without interference with their associates. In other words, plants in a seed-propagated population are expected to segregate for various morphological and physiological characters which could be positively or negatively responsible for competitive ability. Taking such genetic complexity for granted and assuming random combination of genotypes for competitive ability in a pair of adjoining trees, multimodal distribution of tree girths will be more acceptable than bimodality.

In the present study, density response has been measured by growth of $\mathrm{DBH}$ of a single tree growing in the center of a circular plot being surrounded by its associates, on the one hand, and by the mean $\mathrm{DBH}$ of all trees coexisting inside a circle, on the other. Inter-tree competition, on the contrary, has been measured by either the correlation or the difference between DBH's of two neighboring trees.

As briefly described in the opening paragraph of this paper, there has been a conflict of opinion among ecologists, agronomists and geneticists on the relation between density effect and inter-plant competition. Agronomists and ecologists generally appear to take a view that competition is the response of plants to density induced shortages of common resources on the assumption that plants under such circumstances inevitably scramble for the short resources. For instance, Kira, Ogawa and Sakazaki (1953) defined the effect of plant associates growing in a limited area on the growth of a plant as the "competition-density effect" without making a distinction between the two. Not a few papers dealing with problems of inter-plant competition from a similar viewpoint have been published (See for example Harper 1961). Recently Jacquard (1973) set forth his view that the density effect is one aspect of inter-plant competition and should be treated as of the same category. In this connection we can introduce a certain evidence from our experiment conducted before. Sakai, Mukaide and Tomita (1963) investigated inter-tree competition in 13 plantations of Cryptomeria japonica D. Don., three of which were being planted with vegetatively propagated clonal strains and the remaining ten with seed-propagated ones. In this investigation, correlation of stem diameter between two adjoining trees was measured with an expectation that the correlation coefficient would theoretically be minus if competition occurred between them, because it should promote growth of one tree with higher competitive ability, and hinder that of another with lower ability. In practice, the effect of competition to make the inter-tree correlation minus may often counterpoise the plus effect of environments which is due to similarity in environmental conditions in neighborhood. The correlation coefficients between two adjoining trees in the clonal stands were found to be between 0.57 and 0.31 with a mean of $0.437 \pm 0.130$, while in seed-propagated stands, they were between 
0.33 and -0.28 with a mean of $0.024 \pm 0.195$. Thus, it has been concluded that in a clonal population, growth of individual trees may be suppressed by the effect of density, but little sign of inter-tree competition is observed. Of interest in this connection is that Kira, Ogawa and Sakazaki (1953) did find in their soya-bean experiment that in a population of a single cultivar, "the correlation coefficients between the weight of an individual and the mean weight of the nearest six plants were for the most part positive" going against their expectations. The values in the population were as high as 0.645 or 0.735 . This result increased if inter-plant competition did not occur in the population of a soya-bean cultivar. Two years later, some of them (Hozumi, Koyama \& Kira 1955) conducted a similar experiment with maize and found that the correlation between neighboring plants was negative. To the present writers, this appears quite reasonable because soya-bean is a highly self-fertilized plant and a cultivar is most likely a genetically homogeneous population, while maize is an allogamous plant and accordingly a single cultivar may without doubt be genetically heterogeneous.

Those who emphasize inter-plant scramble for common resources as the main cause of competition reason that the most widespread and intensive competition would occur in a group of plants with high genetic similarity, because the genetic resemblance among individuals will bring about the similarity in their requirements (Sammeta \& Levin 1970). Needless to say, the genetic resemblance among groups of plants is highest in a population of vegetatively propagated plants from a single parent (a clone) and a cultivar of self-fertilizing plants continuously propagated from a single plant in each generation. Results of the experiments just mentioned above show that the reasonings are not correct, suggesting that the gene-to-gene bound competition must be an actual occurrence in plant populations.

Fasoulas and Tsaftaris (1975) take the view that "density brings about competition" which suppresses the yield of plants either evenly (in a monogenotypic population) or unevenly, and defined the latter as "allo-competition" and the former as "isocompetition" instead of saying "no-competition".

We have to add here the conclusion drawn from a spacing and mix-planting experiment of 12 barley cultivars conducted by Sakai and lyama (1966). In the spacing experiment it was demonstrated that all cultivars equally showed a very poor growth at a very high density, but as the density decreased, they showed various patterns of growth promotion showing cultivar-specific density response. In the mix-planting experiment with the same cultivars, the twelve barley cultivars were found to be variable for competitive ability among them. By comparing both experiments, it was found that the density response and competitive ability were only partly correlated but not reaching the 0.05 level of statistical significance. 
Thus, it was concluded that the response to plant density and competitive ability were different characters controlled by mostly different groups of genes.

We finally state that the effect of plant density upon growth of plants is the general effect of decreasing growth for all plants concerned, though the amount of decrease may be more or less different due to genotypes. The effect of intraspecific competition is the specific effect of the interaction of genotypes for competitive ability in a given pair of plants to favor growth of one plant at the expense of another. So far not much attention seems to have been paid to the silvicultural significance of genetic variability of density response and intraspecific competition in forest trees, but the problem of density response and competition will be worthy of notice in future tree breeding, particularly in cross-fertilizing tree species with a rapid growth rate as found in the tropical forest trees.

\section{CONCLUSION}

From the analytic study of density response, on the one hand, and competitive ability, on the other, in a plantation of more than 50-year-old Altingia excelsa Noronha trees, the following results have been obtained:

(1) For estimation of density response in the species, measurement of average DBH of all trees growing in circular plots with radii of 5.5 or 6.0 meters or in $10 \times 10$ meter quadrate plots is effectual. In the present plantation it is expected that an increase of one tree would decrease growth of DBH of neighboring trees by 0.75 centimeters.

(2) It has been found that inter-tree competition which favors, two adjoining trees, one tree at the expense of another has occurred in the plantation when two trees grow within a distance of two meters.

(3) The writers hold the view that density response and competitive ability of trees are different characters each probably controlled by different groups of genes though the problem is seen differently among ecologists, agronomists and geneticists.

(4) It is considered that density response as well as competitive ability will be important in future silviculture, particularly in cross-fertilized tree species with high growth rate.

\section{ACKNOWLEDGMENTS}

This study has been conducted as a part of the research activities of the Tropical Forest Biology Program of BIOTROP (SEAMEO Regional Center for Tropical Biology), Bogor, Indonesia. The writers have to express their gratitude to 
BIOTROPIA Vol. 1 No. 1, July-December 1987

Prof. Dr. Ishemat Soerianegara, the former Director of BIOTROP, and also to Prof. Dr. Zoefri Hamzah, the former Tropical Forest Biology Program Manager of BIOTROP for their valuable advice and help in the study.

\section{LITERATURES CITED}

AKIHAMA, T. 1967. Estimation of competitive ability and its relation to fitness in rice hybrid population. Jap. J. Breed. 17: 262-265.

AKIHAMA, T. 1968. Inheritance of the competitive ability and effects of its selection on agronomic characters. Ibd. 18: 12-14.

FASOULAS, A. and A. TSAFTARIS. 1975. An integrated approach to plant breeding and field experimentation. Dept. Genet. \&P1. Br., Aristotelian Univ. of Thessaloniki, Greek, Pub. No. 5: 5-37.

FORD, E.D. 1975. Competition and stand structure in some even-aged plant monocultures. J. Ecol. 63(1):311-334.

HARPER, J.L. 1961. Approaches to the study of plant competition. Symp. Soc. Exp. Biol. 15: 1-39.

HOZUMI, K., H. KOYAMA and T. KIRA. 1955. Intraspecific competition among higher plants. IV. A preliminary account on the interaction between adjacent individuals. J. Inst. Polytech., Osaka City Univ., D 6. p. 121-130.

JACQUARD, P. 1973. Glossary of terms and definition: Fodder crops section, "Competition and Fodder Crop Breeding" (6th issue, April 1973, Eucarpia).

KIRA, T., H. OOAWA and N. SAKAZAKI. 1953. Intraspecific competition among higher plants. I. ompetiton-yield-density interrelationship in regularly dispersed population. J. Inst. Polytech., Osaka City Univ., D 4. p. 1-16.

KOYAMA, H. and T. KIRA. 1956. Intraspecific competition among higher plants. VIII. Frequency distribution of individual plant weight as affected by the interaction between plants. Ibd., D. 7. p. 73-94.

OKA, H.I. 1960. Variation in competitive abilities among rice varieties. Jap. J. Breed. 10: 61-68.

SAKAI, K.I. 1955. Competition in plants and its relation to selection. Cold Spring Harbor Symp. Quant. Biol. 20: 137-157.

SAKAI, K.I. and S. IYAMA. 1966. Studies on competition in plants and animals. XI. Competitive ability and density response in barley. Jap. J. Breed. 16 (1): 1-9.

SAKAI, K.I., H. MUKAIDE and K. TOMITA. 1968. Intraspecific competition in forest trees. Silvae Genetica 17 (1): 1-5.

TANAKA, K. 1983. Changes in diameter and height distribution in a forest stand. J. Jap. For. Soc. 65: 473-476. 